\title{
ESTUDO ANATÔMICO DO LENHO DE SAPIUM HAEMATOSPERMUM MÜLL. ARG. (EUPHORBIACEAE) ${ }^{1}$
}

\author{
ANELISE MARTA SIEGLOCH ${ }^{2}$ JOSÉ NEWTON CARDOSO MARCHIORI ${ }^{3}$ \\ SIDINEI RODRIGUES DOS SANTOS ${ }^{4}$
}

\section{RESUMO}

No presente estudo é descrito o lenho de Sapium haematospermum Müll. Arg., com base em material procedente de São Francisco de Assis, Rio Grande do Sul. Foram observadas as seguintes características anatômicas, comuns em Euphorbioideae e gênero Sapium: anéis de crescimento pouco conspícuos; poros de diâmetro médio, pouco numerosos e em curtos múltiplos radiais; placas de perfuração simples; pontoações intervasculares grandes; parênquima apotraqueal difuso-em-agregados; e raios uni e bisseriados, heterocelulares, com cristais e lactíferos.

Palavras-chave: Anatomia da madeira, Euphorbioideae, Sapium haemastospermum.

\section{ABSTRACT}

[Wood anatomy of Sapium haematospermum Müll. Arg. (Euphorbiaceae)].

The wood anatomy of Sapium haematospermum Müll. Arg. is described, based on material colleted in the municipality of São Francisco de Assis, Rio Grande do Sul state, Brazil. The following anatomical features that are common among woods of Euphorbioideae and genus Sapium were observed: growth rings almost indistinct; few numerous medium vessels, in short radial multiples; simple perforation plates; large intervascular pits; diffuse-in-aggregates apotracheal parenchyma; and uniseriate and bisseriate heterocellular rays, with crystals and laticifers.

Key words: Euphorbioideae, Sapium haematospermum, Wood anatomy.

\section{INTRODUÇÃO}

A família Euphorbiaceae sensu stricto compreende as subfamílias Acalyphoideae, Crotonoideae e Euphorbioideae (Wurdack et al., 2005), sendo que a última distingue-se por apresentar pólen tricolporado, pêlos simples e látex branco, frequentemente cáustico (Judd et al., 2009).

A subfamília Euphorbioideae contém 5 tribos e 54 gêneros (Wurdack et al., 2005), salientando-se Hippomane, Hura, Euphorbia,

\footnotetext{
Recebido em 10-03-2012 e aceito para publicação em 07-04-2012.

2 Mestranda do Programa de Pós- Graduação em Engenharia Florestal, Bolsista-CAPES, Universidade Federal de Santa Maria, CEP 97105900, Santa Maria, RS, Brasil. anesiegloch@yahoo.com.br

3 Engenheiro Florestal, Dr. Bolsista de Produtividade em Pesquisa (CNPq-Brasil). Professor Titular do Departamento de Ciências Florestais, Universidade Federal de Santa Maria.

4 Biólogo, Dr. Departamento de Ciências Florestais, Universidade Federal de Santa Maria. sthurt.bio@ gmail.com.
}

Gymnanthes, Stillingia e Sapium (Judd et al., 2009) por estarem representados na flora brasileira. Com cerca de 125 espécies, pantropicais e em sua maioria americanas (Bacigalupo, 2005), o gênero Sapium apresenta duas espécies nativas no Rio Grande do Sul: Sapium glandulosum (L.) Morong e Sapium haematospermum Müll. Arg. (Alvarez Filho, 1997).

Sapium haematospermum, o popular curupi ou pau-de-leite, distribui-se de Mato Grosso, Goiás e Minas Gerais ao Rio Grande do Sul (Lorenzi, 1998), ocorrendo, ainda, no Paraguai, Argentina e Uruguai (Biloni, 1990; Pompert, 1989). No Rio Grande do Sul, encontra-se no Planalto Médio, Depressão Central, Serra do Sudeste e, principalmente, na Campanha do Sudeste, habitando, sobretudo, em solos arenosos ou superficiais (Marchiori, 2000). Trata-se de árvore com tronco curto, tortuoso, de casca espessa e copa globosa, com raminhos amarelados e folhagem salicácea, caducifólia. As folhas, simples, subcoriáceas e linear- lanceoladas, 
apresentam ápice agudo, base aguda, margem crenulada e 1-2 glândulas sésseis no pecíolo (Marchiori, 2000). A madeira, branca, macia e muito susceptível a deterioração, serve para caixotaria leve, lenha e carvão (Lorenzi, 1998). $\mathrm{O}$ aspecto ornamental da árvore recomenda seu cultivo em áreas amplas, notadamente em parques.

Na literatura anatômica das Euphorbioideae destaca-se a contribuição de Mennega (2005), que estudou 34 gêneros e 84 espécies, abrangendo as cinco tribos da subfamília (Stomatocalyceae, Hippomaneae, Pachystromateae, Hureae e Euphorbieae). Para o conjunto da subfamília, a autora atribui uma grande semelhança estrutural: poros relativamente escassos, pequenos a grandes, em curtos múltiplos radiais e racemiformes; placas de perfuração simples; pontoações intervasculares médias a grandes; pontoações raio-vasculares grandes, semiareoladas, regulares ou irregulares; parênquima apotraqueal ondulado, em faixas estreitas e em agregados; raios uni e bisseriados, fortemente heterocelulares, com exceção de Hippomane, Hura, e Pachystroma, frequentemente com cristais e/ou sílica; fibras por vezes gelatinosas; e lactíferos radiais na maioria dos gêneros, embora escassos e difícil detecção, pela ausência de células epiteliais.

Para o gênero Sapium, a mesma autora menciona: baixa freqüência de poros $/ \mathrm{mm}^{2}$; pontoações intervasculares grandes; fibras com diâmetro de 30-40 $\mu \mathrm{m}$ e 500-900 $\mu \mathrm{m}$ de comprimento, com pequenas pontoações simples ou areoladas, geralmente restritas às faces radiais da parede; freqüência de raios inferior a 10/mm; raios unisseriados com 16-20 $\mu \mathrm{m}$ de altura; e raios multisseriados com $30-70 \mu \mathrm{m}$ de altura. Para Sapium haematospermum, foram observados: anéis de crescimento delimitados por fibras radialmente achatadas e vasos de menor diâmetro no lenho tardio; elementos vasculares ovais, de 60-200 $\mu \mathrm{m}$ (até $270 \mu \mathrm{m}$ ) de diâmetro e1060 (830-1350) $\mu \mathrm{m}$ de comprimento.

Nas obras clássicas de Record \& Hess (1949) e Metcalfe \& Chalk (1972) constam poucos detalhes para o gênero Sapium. Na primeira, são relacionados raios ocasionalmente altos (100 ou mais células de altura), além da presença de canais radiais. Na segunda, constam: vasos com mais de 200 Hm de diâmetro; pontoações raiovasculares circulares, semelhantes às intervasculares; elementos vasculares com cerca de $1400 \mu \mathrm{m}$ de comprimento; parênquima axial em faixas contínuas; raios bisseriados com menos de $1000 \mu \mathrm{m}$ de altura; e presença de sílica na madeira.

O presente trabalho, ao descrever a estrutura do lenho de Sapium haematospermum, visa a contribuir para o conhecimento das espécies de Euphorbiaceae nativas no Rio Grande do Sul.

\section{MATERIAL E MÉTODOS}

O material em estudo consiste de uma amostra de madeira e respectivo material botânico, incorporados ao Herbário do Departamento de Ciências Florestais (HDCF) sob n ${ }^{\circ} 567$, constando os seguintes dados na ficha dendrológica: J.N.C. Marchiori, São Francisco de Assis, RS, 1981.

Para a confecção das lâminas histológicas foram extraídos três corpos de prova $(1 \times 2 \times 3 \mathrm{~cm})$ da parte mais externa do lenho, próxima ao câmbio, orientados para obtenção de cortes nos planos transversal, longitudinal radial e longitudinal tangencial. Outro bloquinho foi também retirado, com vistas à maceração.

A confecção das lâminas histológicas seguiu a metodologia descrita em Burger \& Richter (1991). A maceração foi realizada pelo método de Jeffrey (Freund, 1970). Os cortes anatômicos foram tingidos com acridina-vermelha, crisoidina e azul-de-astra (Dujardin, 1964); o macerado, apenas com safranina (1\%). A montagem das lâminas permanentes foi feita com Entellan.

A descrição baseou-se nas recomendações do IAWA Committee (Wheeler et al., 1989). No caso da percentagem dos tecidos, foram realizadas 600 determinações ao acaso, com auxílio de contador de laboratório, conforme proposto por Marchiori (1980). A abundância de poros 
foi obtida a partir de um quadrado de área conhecida, superposto a fotomicrografias de seções transversais da madeira.

As medições foram realizadas em microscópio Carl Zeiss, no Laboratório de Anatomia da Madeira da Universidade Federal de Santa Maria. Nas características quantitativas, os números entre parênteses equivalem aos valores mínimos e máximos observados; o valor que acompanha a média é o desvio padrão. As fotomicrografias foram tomadas em microscópio Olympus CX40, equipado com câmera digital Olympus Camedia c3000, no Laboratório de Anatomia da Madeira da Universidade Federal do Paraná.

\section{DESCRIÇÃO ANATÔMICA}

Anéis de crescimento: demarcados, fracamente, por delgada camada de fibras radialmente estreitas no lenho tardio e por vasos de maior diâmetro no início do anel seguinte (Figura $1 \mathrm{~A}, \mathrm{~B})$.

Vasos: poucos numerosos $(7 \pm 2,2(4-10)$ poros $/ \mathrm{mm}^{2}$ ), ocupando $10 \pm 6,6 \%$ do volume da madeira. Porosidade difusa. Poros em múltiplos radiais de 2-5, solitários, menos frequentemente racemiformes, de seção circular a oval, com diâmetro médio $(129 \pm 37(47,5-183) \mu \mathrm{m})$ e paredes finas $(4 \pm 0,7(2,5-5) \mu \mathrm{m}$ ) (Figura $1 \mathrm{~A}, \mathrm{~B})$. Elementos vasculares de comprimento médio $(566 \pm 104(310-770) \mu \mathrm{m})$, com placas de perfuração simples, circulares, e apêndices geralmente em uma extremidade. Pontoações intervasculares grandes $(11 \pm 0,6(10-12,5)$ $\mu \mathrm{m})$, alternas, poligonais, por vezes, estendidas, com abertura em fenda elíptica, inclusa, não ornamentada (Figura 1F). Pontoações raiovasculares com aréolas reduzidas, aparentemente simples, alternas, tendentes a opostas, circulares e/ou alongadas, e de diâmetro médio ( $8 \pm$ $0,7(7-9,5) \mu \mathrm{m})$. Espessamentos espiralados e conteúdos, ausentes.

Parênquima axial: representando $18 \pm 2,0 \%$ do volume da madeira; em arranjos apotraqueal difuso-em-agregados e paratraqueal escasso (Figura 1A,B). Séries parenquimáticas de 324 $\pm 93(150-387) \mu \mathrm{m}$, compostas de $2-4$ células (Figura 1F).

Raios: muito numerosos $(14 \pm 1,1(12-15)$ raios $/ \mathrm{mm}$ ), com 1 - 2 células de largura, ocupando $28 \pm 4,7 \%$ do volume da madeira (Figura 1E,F). Raios uni e bisseriados, de $351 \pm 132$ (180 - 590) $\mu \mathrm{m}$ e 9 (5-17) células de altura; heterocelulares, reúnem células procumbentes no corpo central e fileiras de células quadradas e/ou eretas nas margens, frequentemente com cristais (Figura 1C,E,F). Células perfuradas de raios e lactíferos diminutos, presentes. Raios axialmente fusionados, frequentes. Raios agregados, células radiais de paredes disjuntas e células envolventes, ausentes.

Fibras: libriformes, com pontoações simples mais visíveis na face radial da parede; longas (1245 $\pm 136(1020-1500) \mu \mathrm{m})$, com $24 \pm 4(17-35)$ $\mu \mathrm{m}$ de diâmetro, de paredes finas $3,5 \pm 0,6$ (2$4,5) \mu \mathrm{m}$ e seção frequentemente retangular, ocupando $43,7 \pm 4,7 \%$ do volume da madeira (Figura $1 \mathrm{~A}, \mathrm{~B})$. Fibras gelatinosas, ausentes. Fibras septadas, espessamentos espiralados e traqueídeos, ausentes.

Outros caracteres: variantes cambiais, células oleíferas, células mucilaginosas, estratificação e máculas medulares, ausentes. Inclusões minerais, na forma de cristais prismáticos, dispersos em células eretas e quadradas da margem de raios.

\section{ANÁLISE DA ESTRUTURA ANATÔMICA}

A madeira de Sapium haematospermum Müll. Arg. apresenta características típicas da subfamília Euphorbioideae, de acordo com Mennega (2005): anéis de crescimento pouco conspícuos; poros pouco numerosos, de diâmetro médio e em curtos múltiplos radiais; placas de perfuração simples; pontoações intervasculares grandes; parênquima apotraqueal difusoem-agregados; raios uni e bisseriados, heterocelulares, com presença de cristais e lactíferos.

Comparado ao referido por Mennega (2005), o material em estudo apresenta menor número de poros $/ \mathrm{mm}^{2}$, pontoações intervasculares maiores e fibras mais estreitas $(24 \mu \mathrm{m})$, com 

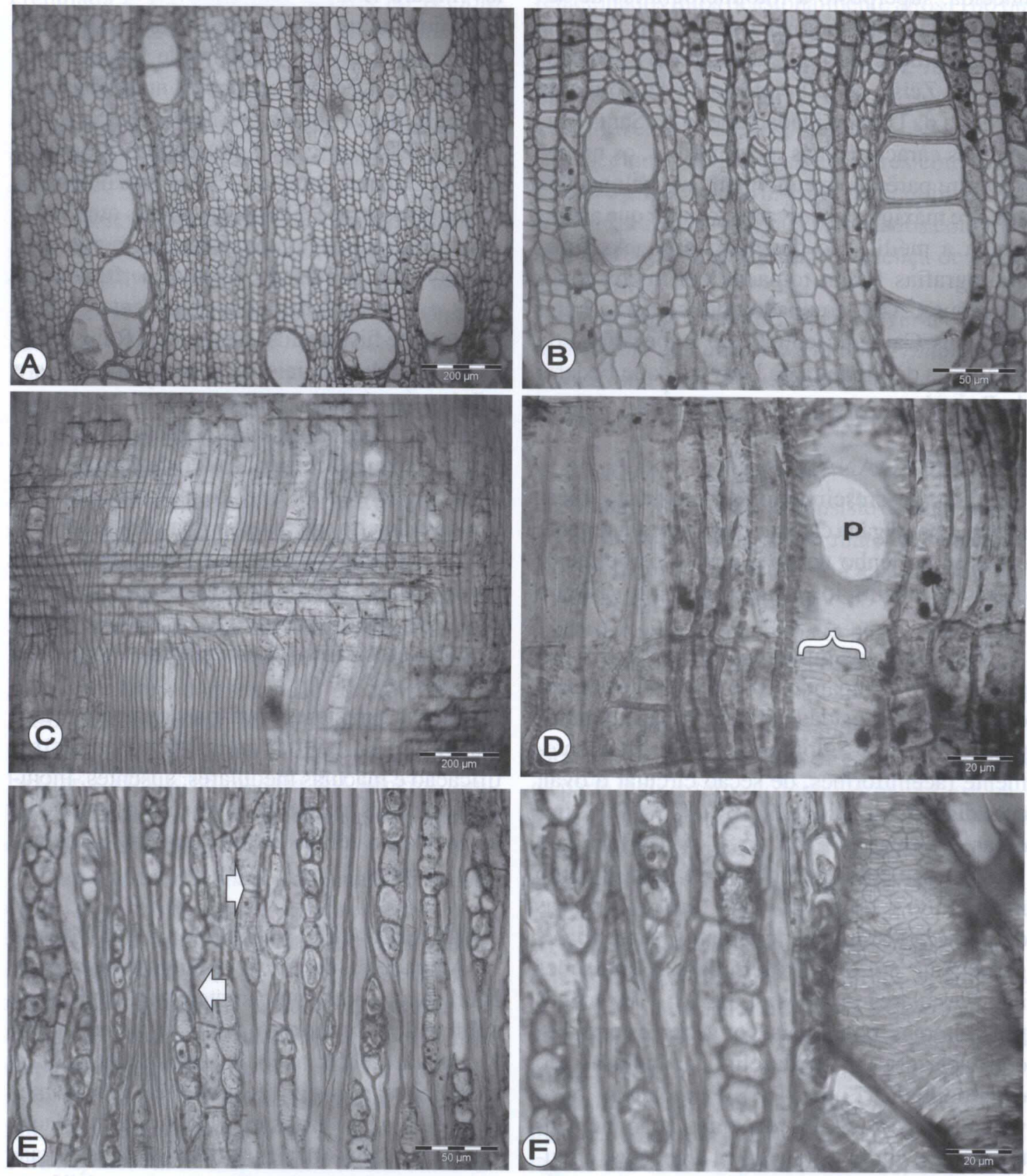

FIGURA 1 - Aspectos anatômicos da madeira de Sapium haematospermum Müll. Arg. A - Seção transversal, mostrando poros solitários, em múltiplos racemiformes, e parênquima apotraqueal difuso-em-agregados. B - Mesma seção, destacando poros em curtos múltiplos radiais, parênquima apotraqueal difuso-em-agregados e fibras de paredes finas. C - Raio heterogêneo, com células procumbentes no corpo central e células eretas e quadradas nas margens, eventualmente com cristais (seção longitudinal radial). D - Seção longitudinal radial, mostrando placas de perfuração simples (p) e pontoações raio-vasculares estendidas, opostas (chave). E - Raios uni e bisseriados e parênquima axial em séries (setas). F - Vasos com pontoações intervasculares poligonais, alternas, e raios unisseriados (seção longitudinal tangencial). 
pontoações simples restritas às faces radiais da parede.

A maior parte das características anatômicas, todavia, concorda com o proposto por Mennega (2005): anéis de crescimento pouco distintos, delimitados por delgada camada de fibras radialmente estreitas no lenho tardio e por vasos de maior diâmetro no lenho inicial; poros circulares ou ovais, com 129 um de diâmetro; e elementos vasculares, com cerca de $566 \mu \mathrm{m}$ de comprimento.

\section{REFERÊNCIAS BIBLIOGRÁFICAS}

ALVAREZ FILHO, A. Estudo das tribos Acalypheae Müll. Arg. e Hippomaneae Reichenb. (Euphorbiaceae) no Rio Grande do Sul-Brasil. Porto Alegre: Universidade Federal do Rio Grande do Sul, 1977. 201 p. Dissertação de Mestrado (Curso de Pós-Graduação em Botânica).

BILONI, J. S. Arboles autoctonos argentinos. Buenos Aires: Tipog, Editora Argentina, 1990. 335 p.

BACIGALUPO, N. M. Euphorbiaceae, Euforbiáceas. In: BURKART, A.; BACIGALUPO, N. M. Flora Ilustrada de Entre Rios (Argentina). Buenos Aires: Colección científica del I.N.T.A., 2005. p. 101-195.

BURGER, L.M.; RICHTER, H.G. Anatomia da Madeira. São Paulo: Ed. Nobel, 1991. 154 p.

DUJARDIN, E.P. Eine neue Holz-Zellulosenfaerbung. Mikrokosmos, n. 53, p. 94, 1964.

FREUND, H. Handbuch der Mikroskopie in der Technik. Frankfurt: Umsham Verlag, 1970. 375 p. JUDD, W. S.; CAMPBELL, C. S.; KELLOGG, E. A.; STEVENS, P. F.; DONOGHUE, M. J. Sistemática vegetal: um enfoque filogenético. Porto Alegre: Artmed, 2009. p. 355-359.
LORENZI, H. Árvores brasileiras: manual de identificação e cultivo de plantas arbóreas do Brasil. Nova Odessa: Editora Plantarum, 1998. 352 p.

MARCHIORI, J.N.C. Comprovação da viabilidade da utilização da secção longitudinal tangencial para a determinação histométrica dos elementos axiais do xilema secundário. In: Anais do IV Congresso Florestal Estadual, Nova Prata, RS, p. 180-184, 1980.

MARCHIORI, J. N. C. Dendrologia das Angiospermas: das Bixáceas as Rosáceas. Santa Maria: Editora UFSM, 2000. 240 p.

MENNEGA, A. M. W. Wood anatomy of the subfamily Euphorbioideae. A comparison with subfamilies Crotonoideae and Acalyphoideae and the implications for the circumscription of the Euphorbiaceae. IAWA Journal, v. 26, n. 1, p 1-68, 2005.

METCALFE, C.R.; CHALK, L. Anatomy of the Dicotyledons. Oxford: Clarendon Press, 1972. p. 1207-1235.

POMPERT, M. G. de. Estudio morfo-anatomico de los especies de Sapium (Euphorbiaceae). Bonplandia, Corrientes, v. 6, n.3, p. 197-210, 1989.

RECORD, S.J.; HESS, R.W. Timbers of the New World. New Haven: Yale University Press, 1949. p. 152-164.

WHEELER, E.A.; BAAS, P.; GASSON, P.E. IAWA list of microscopic features for hardwood identification. IAWA Bulletin, v.10, n. 3, p. 218359, 1989.

WURDACK, K. J.; HOFFMANN, P.; CHASE, M. W. Molecular phylogenetic analysis of uniovulate Euphorbiaceae (Euphorbiaceae sensu stricto) using plastid $R B C L$ and TRNL-F DNA sequences. American Journal of Botany, v. 92, n. 8, p.1397-1420, 2005. 